\title{
MICROBIOLOGICAL PRECIPITATION, MORPHOLOGY AND THERMAL BEHAVIOR OF BARIUM HYDROGEN PHOSPHATE
}

\author{
XIAONIU YU ${ }^{a, b}$, CHUNXIANG QIAN ${ }^{a, b, *}$, XIN WANG ${ }^{a, b}$ \\ a School of Materials Science and Engineering, Southeast University, Nanjing 211189, PR China \\ $b$ Research Institute of Green Construction Materials, Southeast University, Nanjing 211189, PR China
}

\begin{abstract}
The barium hydrogen phosphate (BHP) precipitate was induced using enzymes in the Bacillus subtilis reproduction and structure, morphology and thermal properties of the barium hydrogen phosphate precipitate were characterized by Fourier transform infrared spectroscopy (FTIR), energy dispersive X-ray spectroscopy (EDS), X-ray techniques (XRD), scanning electron microscope (SEM), thermogravimetric-differential scanning calorimetry (TG-DSC) analysis. There is no obvious difference in the composition and structure but the diffraction intensity. Morphology of BHP via microbiological precipitation differs from chemical and biomimetic process, and its brick-like shape is observed. Compared with chemical synthesis, there are bigger total weight-loss (7.47\%) and lower decomposition or melting points $\left(355.5^{\circ} \mathrm{C}\right)$ of BHP by microbiological precipitation, possibly caused by organic matrices.
\end{abstract}

Keywords: Barium hydrogen phosphate; Structure; Morphology; Thermal properties; Fourier transform infrared spectroscopy.

\section{INTRODUCTION}

Barium hydrogen phosphate (BHP), as one of alkaline earth phosphates, has been widely investigated due to their applications in different fields such as bioceramics, ionic conductivity, ferroelectrics, luminescence, metal-doped, and corrosion protection of metal alloys [1-5]. There are a lot of synthetic process to prepare barium hydrogen phosphate, including gel method [6], electrochemical technique [7], hydrothermal synthesis [8], and chemical precipitation using $\mathrm{H}_{3} \mathrm{PO}_{4}$ or $\mathrm{P}_{4} \mathrm{O}_{10}$ in the presence of a base [9-11]. From all these methods, the desired material can be obtained in single crystals and powder form in bulk.

Synthesis of inorganic materials with special shape and structure has been attracted extensive interest by biologists, chemists, and material scientists. By biomimetic process, scientists have used organic matrix as a new class of additives to control morphology or size of inorganic materials, for example, Wang and $\mathrm{Yu}[12,13]$ utilize organic templates to tailor the morphology of barium hydrogen phosphate, and give a variety of crystalline structure. Therefore, organic templates are able to regulate size, morphology, solidstate chemical reactions process of synthesizing particles [14-17]. In recent years, bio-phosphate minerals (microbial-induced phosphate precipitation) are successfully prepared and systematically studied by Qian et al [18-22]. Microbial-induced deposition phosphate is similar with microbe-induced calcite precipitation (MICP), and which can be applied to some actual engineering fields, for example, treatment of sandy soil foundation, remediation of heavy metals in contaminated soil, etc [18-22].

In this paper, we have applied different methods, which contain the chemical, microbial and biomimetic process, to synthesize barium hydrogen phosphate. Its structure and morphology are characterized by Fourier transform infrared spectroscopy (FTIR), energy dispersive X-ray spectroscopy (EDS), $\mathrm{X}$-ray techniques (XRD), scanning electron microscope (SEM), and their results are also analyzed. The morphology, FTIR spectra, and TG-DSC of barium hydrogen phosphate by microbiological precipitation were compared with chemical synthesis.

\section{EXPERIMENTAL}

\subsection{Chemicals}

All raw materials were of analytically pure grade and used without further purification. And Deionized water was self-made.

2.2 Sample preparations

Chemical synthesis of BHP-1: $\mathrm{K}_{2} \mathrm{HPO}_{4} \cdot 3 \mathrm{H}_{2} \mathrm{O}(20 \mathrm{mM})$ was completely dissolved in a flask bottle with $200 \mathrm{ml}$ water. $20 \mathrm{mM}$ of $\mathrm{BaCl}_{2} \cdot 2 \mathrm{H}_{2} \mathrm{O}$ was added to the above solution. After stirring for $2 \mathrm{~min}$, the mixed solution was allowed to stand for $24 \mathrm{~h}$ at an ambient temperature of $26 \pm 2{ }^{\circ} \mathrm{C}$. The products were filtrated and washed three times with deionized water and ethanol and then dried at $66 \pm 2{ }^{\circ} \mathrm{C}$ for $24 \mathrm{~h}$. The chemical sample was collected.

Microbiological precipitation of BHP-2: Cultivation of Bacillus subtilis was conducted in a medium containing $3 \mathrm{~g} / \mathrm{L}$ beef extract, $5 \mathrm{~g} / \mathrm{L}$ peptone and $1 \mathrm{~g} / \mathrm{L}$ sodium chloride. The microbe culture with $\mathrm{OD}_{600}$ value of 1.69 and enzyme activity value of $0.23 \mathrm{mmol} /(\mathrm{L} \mathrm{min})$ was used in this study. Then, harvested microorganisms were kept in a refrigerator at $4{ }^{\circ} \mathrm{C}$ for stock prior to use. $20 \mathrm{mM}$ of phosphate monoester was dissolved in a petri dish with $30 \mathrm{ml}$ water, and the $\mathrm{pH}$ was adjusted to 9.0 using $18 \% \mathrm{HCl}$ solution. Added the solution to $200 \mathrm{ml}$ of bacteria solution, and it was allowed to stand under static conditions for 72 hours at $30 \pm 2{ }^{\circ} \mathrm{C}$ in an oven. As the same procedure mentioned in the "Chemical Method" section, the microbial sample was obtained.

Biomimetic synthesis of BHP-3 and BHP-4: $20 \mathrm{mM}^{\circ}$ of $\mathrm{K}_{2} \mathrm{HPO}_{4} \cdot 3 \mathrm{H}_{2} \mathrm{O}$ was completely dissolved in a flask bottle with $200 \mathrm{ml}$ mixed solution of Bacillus subtilis and phosphate monoester, and Bacillus subtilis solution, respectively. As the same procedure mentioned in the "Chemical Method" section, two samples were also obtained.

2.3 Characterization

X-ray techniques (XRD) (Bruker Company, Germany) analysis was carried out on sample at room temperature by a D8-Discover $\mathrm{X}$ diffraction meter $(40 \mathrm{kv}, 40 \mathrm{~mA})$ with $\mathrm{Cu}(\lambda=1.5406 \AA)$ irradiation at the rate of $0.020 \mathrm{~s} / \mathrm{step}$ in the range of $5-90^{\circ}$. Fourier transform infrared spectroscopy (FTIR) spectra of the samples were recorded using a Nicolet 5700 spectrometer by the KBr pellet technique in the range of $405-4000 \mathrm{~cm}^{-1}$. Scanning electron microscopy (SEM, FEI Company, Netherlands, operating voltage $20 \mathrm{kV}$ ) with a Genesis $60 \mathrm{~S}$ energy dispersive X-ray spectroscopy (EDS) spectroscopy system was used to conduct morphological studies and to measure the elemental compositions of the samples. Thermogravimetric-differential scanning calorimetry (TGDSC) analysis was done between room temperature and $700^{\circ} \mathrm{C}$ at a heating rate of 10 degree/min using a thermoanalyzer (STA449 F3, Netzsch Company, Germany).

\section{RESULTS AND DISCUSSION}

By Comparing BHP of microbial precipitation which is taken as a more complicated process with chemical and biomimetic synthesis. In the process of microbial precipitation, Bacillus subtilis can produce alkaline phosphatase (EC 3.1.3.1) which constantly hydrolyzed phosphate monoester in water, and obtain $\mathrm{PO}_{4}^{3-}$ and various alcohols $[23,24]$. All $\mathrm{PO}_{4}^{3-}$ were changed into $\mathrm{HPO}_{4}{ }^{2-}$ because of the weakly acidic solution of $\mathrm{BaCl}_{2} \cdot 2 \mathrm{H}_{2} \mathrm{O}$, and barium hydrogen phosphate eventually exist in the mixed solution of Bacillus subtilis and phosphate monoester.

The FTIR spectra is effectively used to identify the functional groups of the samples. The FTIR spectra of BHP-1 and BHP-2 is displayed in the Fig. 1. The FTIR spectrum of BHP-1, the band located at $2651.94 \mathrm{~cm}^{-1}$ is assigned the earlier to interionic Ba...O phonon bands [11,25]. Peaks at 2442.53 and $2360.92 \mathrm{~cm}^{-1}$ may result from the rotational band [25]. The $\mathrm{P}=\mathrm{O}$ stretching vibration leads to a distinct band at $1255.99 \mathrm{~cm}^{-1}$. The vibrational absorptions at 1071.54 and $982.03 \mathrm{~cm}^{-1}$ are corresponding to stretching vibrations of $\mathrm{P}-\mathrm{O}(\mathrm{H})$, and the bands at $892.62 \mathrm{~cm}^{-1}$ corresponds to $\mathrm{P}=\mathrm{O}$ deformation [6]. At 582.93 and $536.33 \mathrm{~cm}^{-1}, \mathrm{P}-\mathrm{O}(\mathrm{H})$ wagging and rocking vibrational bands are 
found [25]. In the FTIR spectra of BHP-2, wave number at 3415.16, 2442.81, $1651.61,1439.34,1259.92,1074.43,986.55,894.80,582.93$ and $537.74 \mathrm{~cm}^{-1}$, whose are match with BHP-1 and literature $[6,25]$. The FTIR spectrum of BHP-1 and BHP-2 confirmed that the functional group is $\mathrm{HPO}_{4}{ }^{2-}$.

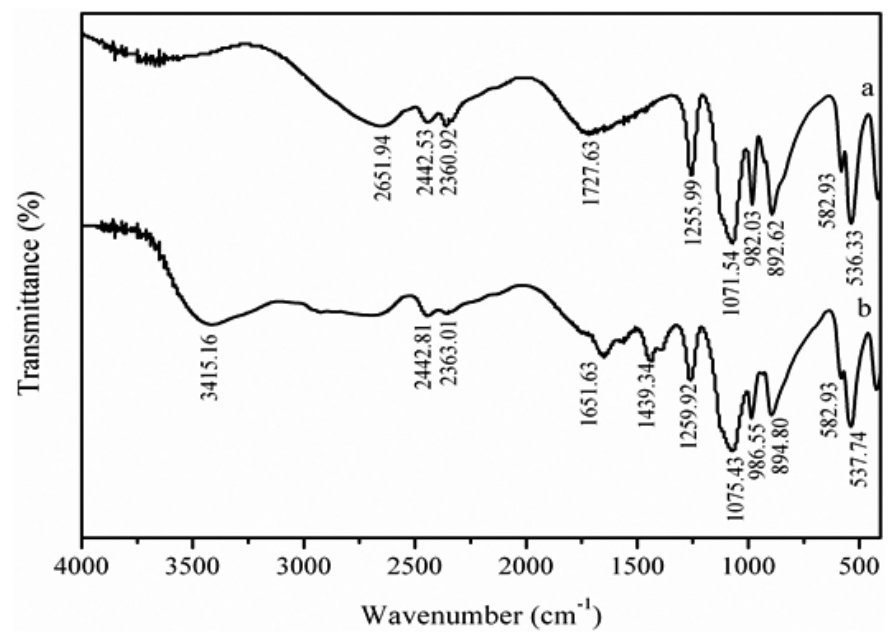

Fig. 1 FTIR spectra of barium hydrogen phosphate: (a) BHP-1, (b) BHP-2.

An elemental analysis of the samples is performed using EDS to confirm the presence of elements $\mathrm{O}, \mathrm{P}$ and Ba in BHP-1, BHP-2, BHP-3 and BHP4 sample (Fig. 2). XRD patterns of BHP-1, BHP-2, BHP-3 and BHP-4 are presented in Fig. 3. Fig. 3 (a), (b) (c) and (d) show that all samples are well crystallized, and all diffraction peaks can be readily indexed to the reported crystal structures of BHP-1, BHP-3, BHP-4 (JCPDS No. 72-1370) and BHP-2 (JCPDS No. 09-0113), and no peaks attributable to impurities are observed.

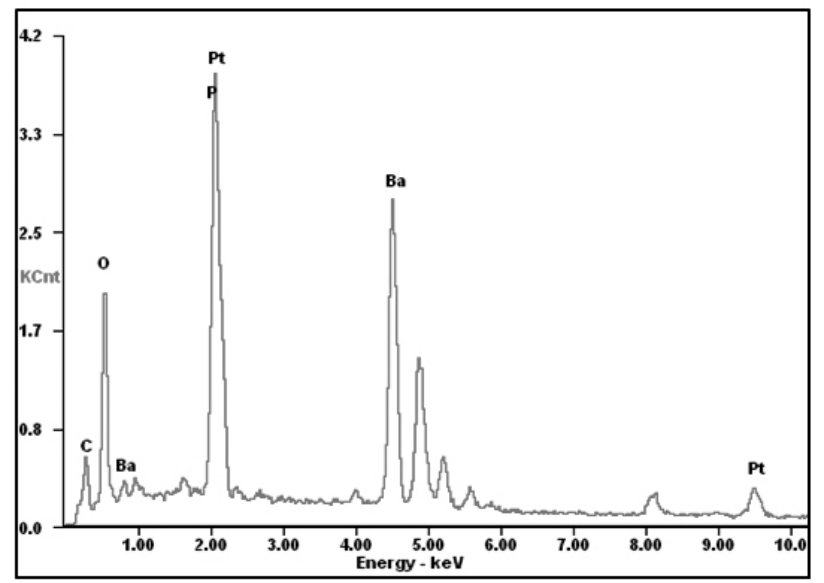

Fig. 2 EDS spectroscopy of barium hydrogen phosphate.

Fig. 4 shows SEM images of BHP-1, BHP-2, BHP-3 and BHP-4 particles obtained under different reaction conditions. Fig. 4 a shows that the morphology of BHP-1 particles is regularly, irregularly quadrilateral box with a relatively smooth surface is observed. A large number of particles are reunited with each other forming big particles flower-like. Fig. $4 \mathrm{~b}$ is the image of BHP2 particles, and debris of small particles on the surface of quadrilateral box is observed. Morphology likes brick and the length is nearly the width twice. However, when $\mathrm{K}_{2} \mathrm{HPO}_{4} \cdot 3 \mathrm{H}_{2} \mathrm{O}$ is dissolved in the mixed solution of Bacillus subtilis and phosphate monoester, particles morphology is similar with BHP-1, as show in Fig. 4 c. Fig. 3 d shows that the morphology of BHP-4 particles is the irregularly quadrilateral box with a rough surface is observed. And the size of particles is nonuniform, which has diameter ranges from 5 to $10 \mu \mathrm{m}$.

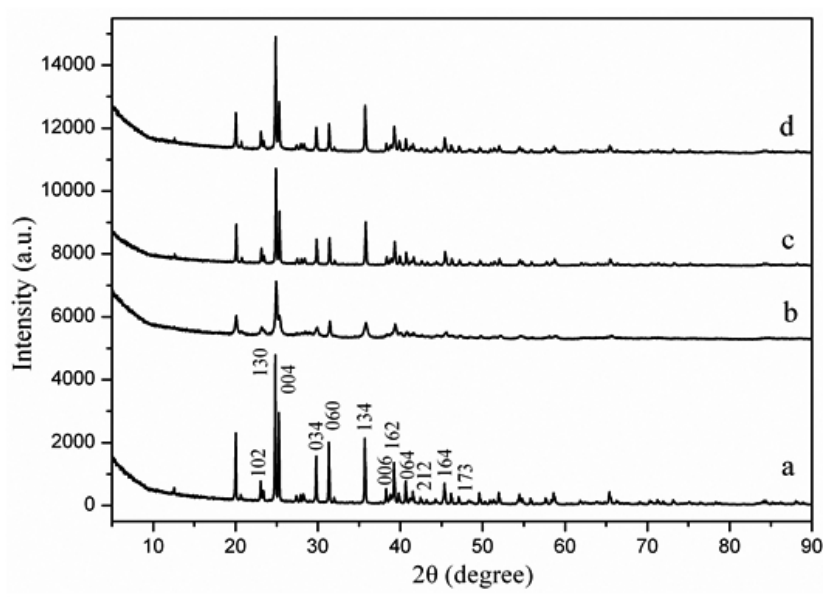

Fig. 3 XRD patterns of barium hydrogen phosphate: (a) BHP-1, (b) BHP2, (c) BHP-3, (d) BHP-4.

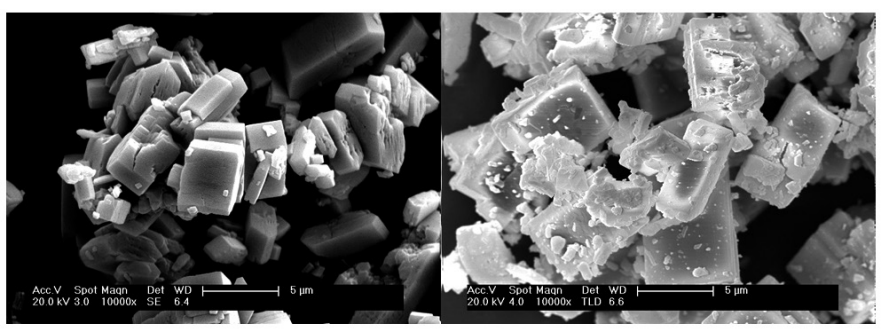

(a)

(b)

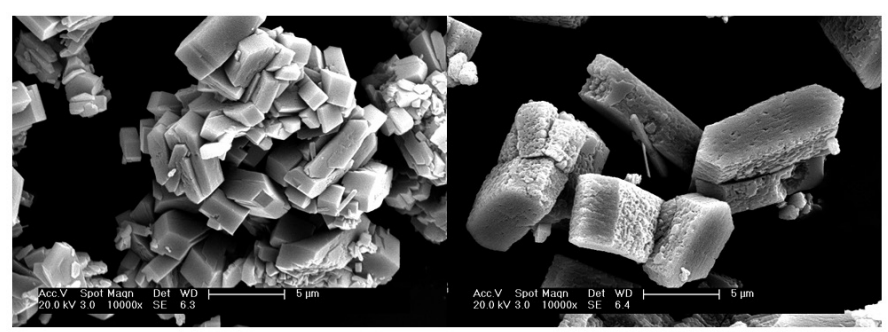

(c)

(d)

Fig. 4 SEM images of barium hydrogen phosphate: (a) BHP-1, (b) BHP-2, (c) BHP-3, (d) BHP-4.

DSC-TG curves of BHP-1 and BHP-2 are displayed in Fig. 5. From the results, it is observed that DSC curves show endothermic peaks at $470.8^{\circ} \mathrm{C}$, $355.5^{\circ} \mathrm{C}$ for BHP-1, BHP-2, respectively. These values can be considered as the decomposition or melting points of the materials. From the results, it is noticed that BHP-1 have more thermal stability than BHP-2 and it may be due to decrease in bond energy caused by containing a small amount of organic matrix. The TG curves of BHP-1 indicate that maximum weight loss occurs in the temperature range room temperature to $700^{\circ} \mathrm{C}$ and with weight-loss of $4.94 \%$ which is due to the decomposition of the samples. Over the same as temperature ranges of BHP-1, the TG curve of BHP-2 shows continuous weight-loss of $7.47 \%$, which does not consist with the weight-loss of BHP-1. The experimental DSC-TG of BHP-1 results obtained in this work is found to be matched with reported in the literature [11].

\section{CONCLUSIONS}

Results of this research provide a new method to synthesize special shape and size BHP. Chemical composition of BHP by microbiological, chemical, biomimetic precipitation can be well characterized by FTIR, EDS, XRD. Microbiological precipitation of BHP has quadrilateral crystalline structure which is similar with chemical and biomimetic process, and its decomposition or melting points is lower than chemical synthesis, possibly caused by organic matrices. 

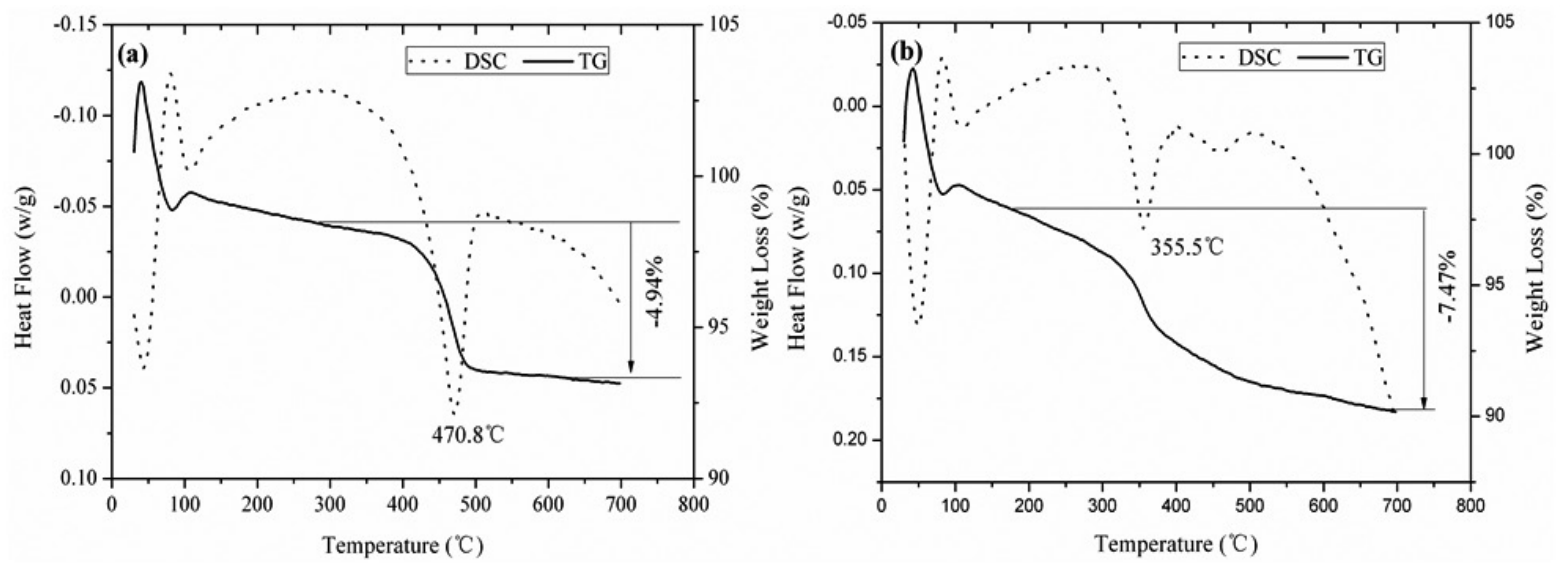

Fig. 5 Thermogravimetric analysis (TG-DSC) of barium hydrogen phosphate: (a) BHP-1, (b) BHP-2.

\section{ACKNOWLEDGEMENTS}

This work was supported by the National Nature Science Foundation of China (Grant No. 51372038), Scientific Research Foundation of Graduate School of Southeast University (Grant No. YBJJ1453), and 333 Project of Jiangsu Province.

\section{REFERENCES}

1.- S. K. Arora, A.T. Oza, T.R. Trivedi, V. A. Patel, Mat. Sci. E. B 77, 131, (2000)

2.- T. R. Trivedi, A.T. Oza, V.A. Patel, S.K. Arora, Cryst. Res. Technol. 35, $615,(2000)$

3.- D. Nallamuthu, P. Selvarajan, T.H. Freeda, International Journal of Pure and Applied Physics 6, 353, (2010)

4.- D. Nallamuthu, P. Selvarajan, T.H. Freeda, Physica B 405, 4908, (2010)

5.- Y.G. Chen, B.L. Luan, G.L. Song, Q. Yang, D.M. Kingston, F. Bensebaa, Surf. Coat. Tech. 210,156, (2012)

6.- K.C. Hebbar, S.M. Dharmaprakash, P.M. Rao, J. Mater. Sci. Lett. 10, 1430, (1991)

7.- M. Dinamani, P.V. Kamath, Mater Res. Bull. 36, 2043, (1997)

8.- T. B. Chaabane, L. Smiri, A. Bulou, Solid State Sci. 6,197, (2004)

9.- D.Y. Pan, E.R. Yuan, H.Q. Sun, S.Y. Guo, X.Q. Wang, X.L. Duan, C.N.
Luan, Z.F. Li, Cryst. Res. Technol. 41, 236, (2006)

10.- B.J. Boonchom, C. Ruttanapun, M. Thongkam, P. Chaiyasith, S. Woramongkonchai, S. Kongteweelert, N. Vittayakom, Adv. Mater. Res. 717, 37, (2013)

11.- H.A. Höppe, M. Daub,O. Oeckler, Solid State Sci. 11, 1484, (2009)

12.- F. Wang, G.Y. Xu, Z.Q. Zhang, Mater. Lett. 59, 808, (2005)

13.- X. Yu, C. Qian, X. Wang, Asian J. Chem. 26, 8166, (2014)

14.- S. Mann, Nature 332, 119, (1988)

15.- S. Mann, B.R. Heywood, S. Rajam, J.D. Birchall, Nature 334, 692, (1988)

16.- M. Sarikaya, C. Tamerler, A.Y. Jen, K. Schulten, F. Baneyx, Nat. Mater. 2, 577, (2003)

17.- Y. Oaki, H. Imai, J. Am. Chem. Soc. 126, 9271, (2004)

18.- X.N. Yu, C.X. Qian, X. Wang, Dig. J. Nanomater. Bios. 10, 199, (2015).

19.- X. Yu, C. Qian, X. Wang, Dig. J. Nanomater. Bios. 9, 1373, (2014)

20.- X. Wang, C. Qian, X. Yu, Appl. Biochem. Biotech. 173, 1003, (2004)

21.- X. Yu, C. Qian, X. Wang, Asian J. Chem. 26, 7477, (2014)

22.- X. Yu, C. Qian, B. Xue, X. Wang, Constr. Build. Mater. 82, 167, (2015)

23.- M.G. Roig, F.J. Burguillo, A.D. Arco, J.L. Usero, C. Izquierdo, M.A. Herraez, Int. J. Biochem. 14, 655, (1982)

24.- M.H.L. Du, C. Lamoure, B. H. Muller, O. V. Bulgakov, E. Lajeunesse, A.M. Ânez, J.C. Boulain, J. Mol. Biol. 316, 941, (2002)

25.- S.K. Arora, T.R. Trivedi, A.T. Oza, V.A. Patel, Acta. Mater. 49, 2103, (2001) 